\title{
PLATO AND THE DICE: A REASSESSMENT OF THEAETETUS I54A-I55D
}

Mario Piazza ${ }^{\star}$

University of Chieti-Pescara, Italy

This paper focuses on the pair of philosophical puzzles, in the first section of Plato's Theaetetus, concerning the comparison between cardinalities and sizes. My initial task is to analyse some difficulties and distractions which affect our understanding of the argumentation that Socrates puts forward on Protagoras' behalf. I then offer a revised interpretation that integrates the puzzles with the rest of the Protagorean/Heraclitean theory. The emerging discussion, far from being a bridging passage or detour, is a unit with its own specific identity. Its goal is to stretch the Protagorean/Heraclitean metaphysics of events to a new limit: the dematerialisation of change. Change may also be the simple effect of quantitative comparisons as such. At the same time, important traces of Plato's indirect move against Protagoras are detected: the conceivability itself of this Protagorean view descends from a common application of mathematics.

\section{Introduction}

SOC.: Take six dice ( $\dot{\alpha} \sigma \tau \alpha \gamma \alpha \dot{\alpha} \lambda o v \varsigma){ }^{.}{ }^{\mathrm{I}}$ If you put four besides them, we say that they are more than the four, in fact one and a half times as many; and if you put twelve beside them, we say they're fewer, in fact half as many. And we can't allow the case to be differently described; or will you allow it?

THT.: No.

SOC.: Well now, suppose that Protagoras, or anyone else, asks you this: 'Theaetetus, is there any way in which something can become larger or more numerous, other than

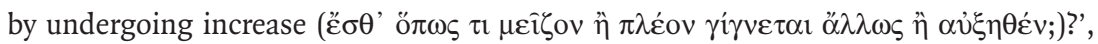
What will you answer?

* Email: m.piazza@unich.it.

I wish to thank two anonymous readers for CCJ for their useful comments.

I $\dot{\alpha} \sigma \tau \rho \alpha \gamma \alpha \dot{\lambda} \lambda \mathrm{ol}$ are four-sided ankle bones of sheep or goats. The other occurrence of the term $\dot{\alpha} \sigma \tau \rho \alpha \gamma \alpha \dot{\lambda} \lambda \mathrm{o} \varsigma$ in the Platonic corpus is in Lysis (206e7). The Greek term closest to our dice is кúßos, for instance mentioned by Aristotle in discussing dice-throwing as an activity governed by luck (Eud. Eth. 8, I247a2I-23; b15-I8). Throughout this paper I have employed the database of the Perseus Digital Library (www.perseus.tufts.edu/ hopper/). 
THT.: If I answer by saying what I think with a view to this present question, Socrates, I'll say that there isn't. But if I answer with a view to the one before, I'll be on my guard against contradicting myself and say that there is.

SOC.: Good, by Hera! Excellent, my friend! Still, if you answer that there is, it looks as if it'll turn out like that tag from Euripides: we'll find that your tongue is irrefutable, but not your heart.

(Tht.I54c2-d6) ${ }^{2}$

The twin puzzles in the first section of the Theaetetus involving the comparison of numbered groups of objects (see the quotation above) and measurable properties of the human body (see I55b5-c4) have notoriously confounded Platonic scholarship. On the one hand, no moral is explicitly drawn from them; on the other, at first glance the solution to them is too obvious for them even to be genuine puzzles. Accordingly, they have been regarded at best as a crux interpretum and at worst as 'an infantile disease of philosophy' (Russell). ${ }^{3}$

In effect, a bundle of intertwined difficulties makes it hard to disentangle the passage from I54a to I55d clearly enough to understand its philosophical dimension. In this section, I shall analyse a whole set of knots: textual, contextual, philosophical. This analysis also aims to explain why I believe the current interpretations of the passage to be in many respects either unconvincing, misleading or incomplete. In the remaining sections, I shall propose an account of the puzzles which revives the reading which was sketched fifty years ago by Richard S. Bluck, and is only rarely discussed in the recent literature. ${ }^{4}$ Bluck's two-page paper, however, leaves unexplained or unnoticed crucial junctures of the argumentation which Socrates puts forward on Protagoras' behalf. ${ }^{5}$ My interpretation attempts to fill these lacunae with a view to reconstructing Plato's strategy in this part of the dialogue.

\subsection{Intricacy}

It hardly needs to be said that any prospect of interpreting the puzzles must take into account the intricacy of the relevant background: the incipient discussion of Theaetetus'

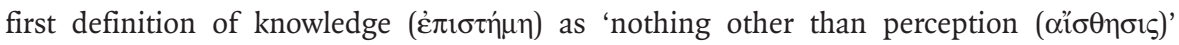
(I5Ie2-3), followed by the first exposition of the core of the Protagorean/Heraclitean theory (I52a-I54a) which goes far beyond the bare import of the 'Man the Measure' dictum (152a3-4). More precisely, the pair of puzzles occupies the exact middle of the textual arch leading from the so called 'Secret Doctrine' - 'as a result of movement,

2 I follow John McDowell's translation, with slight modifications where necessary.

3 Note that Socrates speaks of example $(\pi \alpha \rho \alpha \dot{\delta} \delta 1 \gamma \mu \alpha)$ and no Greek term in this part of the text is actually translated as 'puzzle' by modern translators ('puzzle' is the word employed by Cornford (1935) 43 for the unspecific $\tau$ otoú $\tau \omega \mathrm{V}$ at $\mathrm{I} 55 \mathrm{c} 6)$.

5 In this paper all references to the philosopher Protagoras and to his doctrine are to them as portrayed by Socrates in the dialogue. 
change and mixture with one another ( $\pi \rho \grave{\varsigma} \varsigma \not \partial \lambda \lambda \eta \lambda \alpha$ ), all the things which we say are, are coming to be' $\left(\mathrm{I}_{5} \mathrm{~d} \mathrm{~d} 7-8\right)$ - to the causal account of the Heraclitean mechanism of

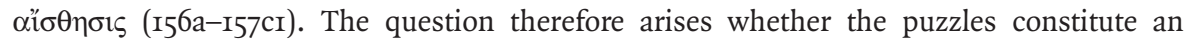
insulated digression - perhaps devoid of any substantive function, on Bertrand Russell's trenchant view: 'the puzzles are not very germane to the argument, and may be ignored' 6 - or rather an integral aspect of the discussion of the Protagorean/Heraclitean doctrine as a whole.

Moreover, the puzzles are embedded within a dialogue phase that exhibits Plato's ability to use the same material to different ends. Socrates is pursuing a strategy on Protagoras' behalf: he presents the Protagorean/Heraclitean metaphysical and epistemological theses in such a way as to demonstrate the equation of knowing with perceiving. From the outset sense perception gains infallibility - Plato's hallmark of knowledge - by virtue of the relational nature of sensible qualities (I52C5-6). At the same time, Socrates' investigation of the Protagorean/Heraclitean doctrine is creative, aiming to transform Theaetetus from passive reader of a text by Protagoras ('you've read that, I take it?', I52a4; cf. I55ег; I6Ic4; I62aI-3; I66d2; I70e9-I7IaI; I7Ib7, c6) into an active participant in the process of understanding extraneous doctrines. Socrates' effort to shore up the Protagorean theory is displayed to the extent that Theaetetus signals his inability to tell whether Socrates is expressing his personal opinions or testing him out ( $\dot{\alpha} \pi \mathrm{o} \pi \varepsilon 1 \rho \hat{\omega} \mu \alpha \mathrm{l})$ (157c4-6). Socrates will, however, dismantle this intellectual apparatus piece by piece in later stages of the discussion ( $16 \mathrm{IC}-\mathrm{I} 83 \mathrm{c})$. Hence the commentator is encouraged to appraise whether Socrates' discussion of the puzzles envisages built-in elements of an anti-Protagorean agenda.

At any rate the discussion of the puzzles ends with Theaetetus acknowledging his state of wonder and Socrates famously characterising this condition/affection ( $\pi \alpha \dot{\theta} \theta \varsigma$ ) as the exclusive source of philosophy (I54c8-d8). ${ }^{7}$ This means that the reader should be more inclined to ponder the philosophical significance of these puzzles as a source of wonder than to regard them as unsophisticated muddles, within a dialogue riddled with references to astonishment from the very first words of the prologue (I42a3). Hence the quest for an interpretation that produces a level of philosophical significance strong enough to justify the evocation of wonder, the most epistemic of human emotions.

\section{2. $154 \mathrm{~b}$}

After formulating and defending a thesis of the Protagorean/Heraclitean world view, Socrates introduces at $154 \mathrm{C} 2-5$ the example of the dice (henceforth: (Dice)) as a little

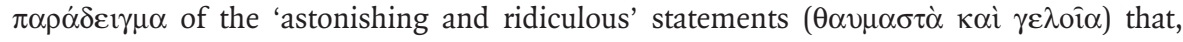

6 Russell (1945) I50.

7 Socrates' phrase 'philosophy has no other starting-point [than wonder]' presents a certain degree of ambiguity, according to whether the point of departure is intended as an historical or an epistemic event. Aristotle maintains both readings (Metaph. I, 2, 982bi2-I3). 
according to Protagoras, the non-Protagorean (I54b6-8) is forced ( $\alpha \nu \alpha \gamma \kappa \alpha \dot{\zeta} \omega)$ to accept. It is customary to assume that astonishing and ridiculous are the conclusions that the nonProtagorean draws from assumptions other than those employed by the Protagorean. But granted the feeling of necessity, it remains far from obvious how this train of thought is supposed to run. After all, if Plato's aim is to indicate the gulf between the non-

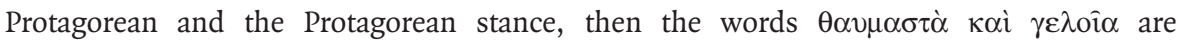
unnecessarily strong: why should the sophist qualify commonsensical statements about change as astonishing and ridiculous, if it would suffice to say that he considers them to be wrong? I have an alternative interpretation for what Socrates might have in mind which, since it embodies substantive claims I will make in the course of the paper, I will postpone until the last section.

The Protagorean thesis and its explanation occupy this highly compressed portion of text (I54bi-6):

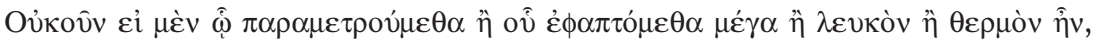

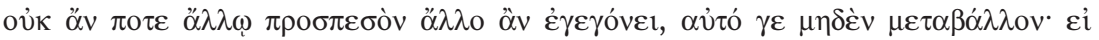

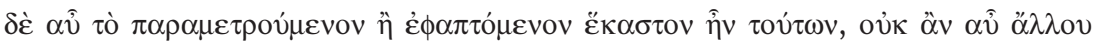

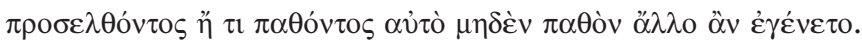

Therefore, if what we measure ourselves against or touch had been large, white, or hot, it would never have become different by bumping into a different person, if at any rate it itself didn't undergo any change. And on the other hand, if what does the measuring or touching had been any of those things, then again, it wouldn't have become different when another thing comes up against it, or the thing which came up against it had something happen to it, if it itself hadn't had anything happen to it. $^{8}$

The negative thesis just enunciated by Socrates is clear enough in placing ontological constraints on the Protagorean epistemology:

(T) the thing that we measure ourselves against and the thing which measures itself against the object are not actually large or white or hot.

The verb $\pi \alpha \rho \alpha \mu \varepsilon \tau \rho \varepsilon \dot{\varepsilon} \omega$ (I54bi; b4) is evidently homage to Protagoras' term of art $\mu \varepsilon \dot{\tau} \tau$ ov and appears nowhere else in the Platonic corpus. The thesis (T) links up with the preceding

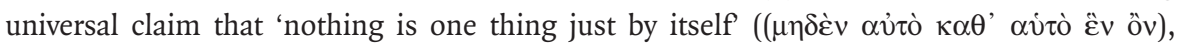
I53e4-5; I52d3-2; I56e8-I57aI; I82 b3-4). Details of this claim have just been provided by Socrates in discussing the ontology of colours. It is argued that there is no way to ascribe any chromatic property to an object without mentioning its reciprocal partner, i.e. the

8 I have slightly modified McDowell's translation. Lewis Campbell stresses that at $154 \mathrm{~b} 2$ the verb 'had been' ( $\hat{\eta} v)$ is emphatic. Campbell (I86I) 44. 
individual percipient for whom exclusively at a certain temporal point that property exists (I53d8-I54a2). ${ }^{9}$ However, even though (T) hinges upon the interaction between an external object perceived and a perceiving subject (or his sense organs), I agree with Bluck in assuming that the range of $\tau$ ò $\pi \alpha \rho \alpha \mu \varepsilon \tau \rho o v \operatorname{\mu \varepsilon vov}$ at $154 \mathrm{~b} 4$ is intended to include human subjects as well as physical particulars whatsoever they may be, including dice. $^{\text {Io }}$

Disappointingly, however, the explanation for $(\mathrm{T})$ is cryptic enough to lead to uncertainty as to why (Dice) is set out as a case in point at this stage of the discussion. To limit myself to the first part of $(\mathrm{T})$, the corresponding explanation is embedded in the counterfactual conditional (protasis: $\varepsilon \dot{\imath}+$ imperfect indicative; apodosis: ő́ + pluperfect indicative

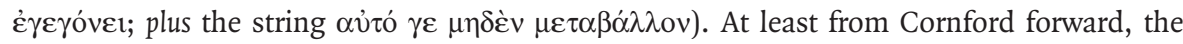
dominant reading of the counterfactual is as follows:

I54bI-3: if what we measure ourselves against had been, e.g., large, white, hot, then it would never have become different by bumping into a different perceiver,

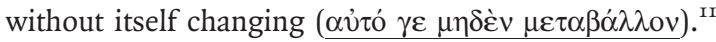

Hence: the thing we measure ourselves against becomes different without undergoing any change itself. For ease of reference, let us call this rendering of the participial expression

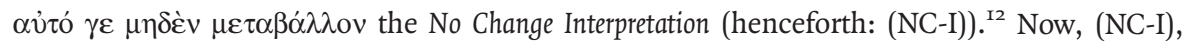
as it stands, produces a discontinuity in the Heraclitean landscape too striking to be ignored. $^{13}$ (NC-I) is not assimilable to any of the various brands of Heracliteanism expounded in the dialogue, on the wake of the initial claim, based on a sapientium consensus, that 'nothing ever is, but things are always coming to be' (I52er). And in particular (NC-I) turns out to be antithetical to the version of the doctrine of flux which

9 'What we say a given colour is will be neither the thing which collides ( $\tau$ ò $\pi \rho \circ \sigma \beta \dot{\alpha} \lambda \lambda$ ov) nor the thing it collides

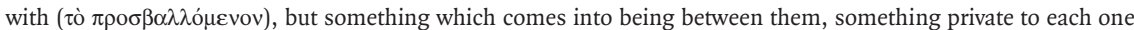

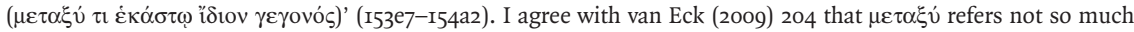
to a spatial location as to something (ontologically) intermediate between the two items, in line with other Platonic passages (cf. Sym. 202a5-9).

io Bluck (I96r) 8.

II As has been pointed out by a reader of this journal, $\mu$ n plus participle has a conditional import. Accordingly, the ifclause comes closer to the Greek text than 'without itself changing' (Levett, Fowler, Chappell). Anyway we can also express such conditional force as a supposition - as Cornford (I935) 40 does ('supposing it to undergo no change in itself - so that 'without itself changing' can be regarded as comprising this supposition.

I2 This reading is defended by, among others, McDowell (1973) I32; Burnyeat (I979) 79; Bostock (I988) 59; Lee (2005) IOI; van Eck (2009) 205 and 212.

I3 The importance of this discrepancy has been emphasised by Fine (1996) ir6. She also argues that the text at I54bi-3 leaves open the possibility that the object has changed: 'if the object is white, then it will not become different, when it appears different, unless it changes [...] Therefore, either it is not white, or else it becomes different and so changes'. Fine (1996) II9-20. Nevertheless, as van Eck points out, the counterfactual construction must be taken as implying that the object was not white and has become different. Cf. van Eck (2009) 203. 
will emerge later in the course of the discussion as the 'correct' (i.e., logically inescapable) one: the hyper-flux version (I8re5-I82ar). In response, it might be suggested that at this stage of the exposition it is still possible that Socrates introduced the specification $\alpha$ $\tau$ 'o $\gamma \varepsilon \mu \eta \delta \dot{\varepsilon} v$ $\mu \varepsilon \tau \alpha \beta \alpha \dot{\alpha} \lambda \lambda \mathrm{v}$ with the purpose of making the flux doctrine somewhat less radical and thus giving it a new appearance of plausibility. But, we may ask, if Plato intended this specification to convey a novelty or a doctrinal compromise in the discussion, why encapsulate it within the coda of a counterfactual? And how can we reconcile a substantive new condition with an explanatory goal? It is thus difficult to resist the conclusion that without a clear understanding of the philosophical role that such deradicalisation of the flux doctrine is supposed to play, the message of (NC-I) becomes utterly mysterious from a general Heraclitean standpoint.

Let us examine the genesis of the explanation of $(\mathrm{T})$ a little more carefully. The oúkov̂v of I54bi is asserted, Gilbert Ryle would say, with a 'logical tone of voice': it is inferential ('and so/therefore'). More precisely, Socrates develops an argument from certain premises that have been introduced under the guise of rhetorical questions (I54a6-8):

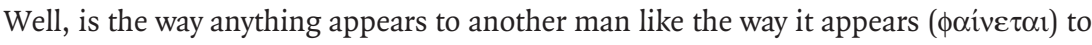

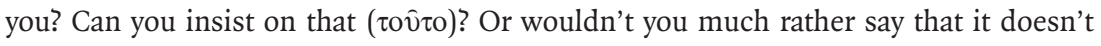
appear the same even to yourself, because you never remain the same as yourself ( $\delta i \dot{\alpha}$

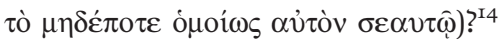

The text contains three distinct claims. Rephrased from a third-person perspective, each of them can be presented as a universal statement:

(CI) Everything appears different to everyone;

(C2) Nothing appears the same to oneself;

$\left(C_{3}\right)$ Nobody remains the same person over time.

Both claims (CI) and $\left(\mathrm{C}_{2}\right)$ are epistemological insofar as they involve the notion of appearance. The third claim $\left(C_{3}\right)$, introduced as an explanation of $\left(C_{2}\right)$, concerns the ontology of person: the perceiver never remains the same from time $t$ to $t^{\prime} .{ }^{15}$ From a logical standpoint, it is worth remarking that $\left(\mathrm{C}_{2}\right)$ is not an independent claim, for it is implied by $\left(\mathrm{CI}_{\mathrm{I}}\right)$ and $\left(\mathrm{C}_{3}\right)$. Indeed, if nothing appears to the individual $S$ like the way it appears to another individual, and $S$ has to be regarded as a succession of momentary

I4 I have slightly modified McDowell's translation.

I5 The main use of $\left(C_{3}\right)$ is deferred till $159 \mathrm{a}-\mathrm{d}$ when the fragmentation of personal identity blocks the charge that false perceptions in dreams are counterexamples to the equation of knowing with perceiving. The Protagorean reply is that the sleeping Socrates and the waking Socrates are different persons (I58cI-I59c6). 
subjects, then at a later time $t^{\prime}$ nothing can appear to $S$ as at $t$, there being at $t^{\prime}$ a subject $S^{\prime}$ that is different from the preceding self $S .{ }^{16}$

Anyway the passage at $\mathrm{I} 54 \mathrm{~b}$ does not directly apply (CI), but a proposition that a Protagorean takes as its direct consequence, i.e.:

$\left(\mathrm{CI}^{\prime}\right)$ Everything becomes different upon coming into contact with other people.

Presumably the line of reasoning leading to $\left(\mathrm{CI}^{\prime}\right)$ rests on the claim that if everything appears different to everyone (CI), then everything is different for everyone (by I52a6-8), where 'being different' boils down to 'becoming different' (I52er; I57aI-2). However, it seems to me that another drawback of (NC-I) is that it reduces the explanatory credentials of the counterfactual at $154 \mathrm{bI}-6$ regarding the thesis (T) that things are not large or white or hot. Indeed, if, as per $\left(\mathrm{CI}^{\prime}\right)$, every object $x$ we measure ourselves against becomes different by bumping into a different perceiving subject, then the coda 'even while $x$ does not undergo any change itself is either dispensable in explaining ( $\mathrm{T}$ ), or might even be adverse to it. Let us call this the explanatory objection. The lesson from it is that we cannot assess the explanatory role of the counterfactual at I54bI-3 without determining the additional value of the string $\alpha \cup \dot{\tau o ́} \gamma \varepsilon \mu \eta \delta \dot{\varepsilon} v \mu \varepsilon \tau \alpha \beta \alpha \dot{\alpha} \lambda \lambda o v$. This is what we shall do in section 2.

\subsection{Lost in intuition}

Other conceptual obscurities in the passage come from two salient gaps between the formulation of (Dice) and the question at $154 \mathrm{c} 8-9$ which follows at its heel. Modern translators tend to isolate the modal profile of the question: 'is it possible to become [...]?' (Levett/Burnyeat); 'can anything become [...]?' (Fowler, Cornford). McDowell's

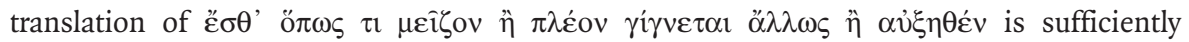
literal in respecting the prevalence of the how over the whether:

(Q154c8-9): is there any way in which something can become larger or more numerous, other than by undergoing increase?

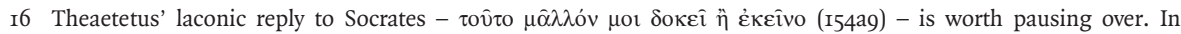
McDowell's translation ('Yes, I think that's nearer the truth than the first alternative') the word 'alternative' is unfortunate, since $\left(\mathrm{Cr}_{\mathrm{I}}\right)$ and $\left(\mathrm{C}_{2}\right)$ do not fall into an oppositional pair. At any rate, there is a general consensus among translators that the boy's reply expresses a preference for $\left(\mathrm{CI}_{\mathrm{I}}\right)$ over $\left(\mathrm{C}_{2}\right)$, as an instance of the norm

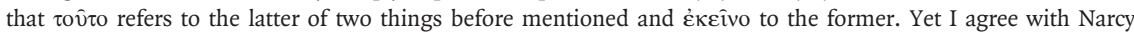
(1995) 323-4 that the referent of the demonstratives should be inverted, a rare but not unparalleled use (see

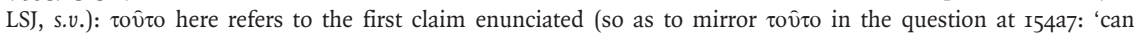

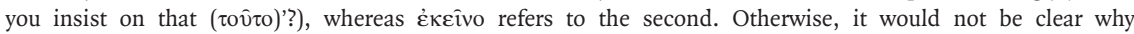
Theaetetus has more confidence in the claim that nothing appears the same to oneself than in the claim that nothing appears to a perceiver like the way it appears to another. In fact $\left(\mathrm{C}_{2}\right)$, witness the explanation attached to it, seems more demanding than $(\mathrm{CI})$, which is a generalisation of the claim about colour appearances at I54a3-4. 
The first disturbing gap (Gap I, for short) is that (QI54c8-9) raises expressis verbis a problem about becoming, while in (Dice) such a notion is conspicuous only by its absence, as made apparent by the verb Eiv $\alpha$ r representing the numerical relations. Rather, (QI54c8-9) seems to take us back to the lines at $154 \mathrm{~b}$ prefacing (Dice). Accordingly, one way to close Gap I is simply to rephrase (Dice) in terms of (relational) becoming: the six dice become more than the four. At first glance, this move seems perfectly consistent with a doctrine whereby everything is constantly changing: the replacement of 'be' with 'become' is the norm in Heraclitean jargon ( $\mathrm{I}_{57} \mathrm{~b}_{2}-3$; $\left.\mathrm{I}_{52} \mathrm{~d} 7-\mathrm{er}\right)$. Yet, on reflection such rephrasing proves not to be pertinent. First, even though (Dice) is part of a Protagorean training under the influence of the flux doctrine, its mathematical language seems to be exempt from the constraints of a special doctrinal commitment. ${ }^{17}$ However, the very deliberateness of the arithmetical background, as we shall see in subsection 3, can be subsumed under another kind of philosophical goal.

Second, most importantly, the option of rephrasing (Dice) in terms of becoming is highly suspect from a theoretical point of view. The reason is that it entails the claim that the group of six dice becomes more/less numerous than another group which, in respect to a hypothetical surface, comes out of nowhere ('take six dice. If you put four beside them [...]'). In other words, this option clashes with a strong intuition we have about the way an object becomes comparatively different in relation to something else: it is possible that when John enters a room he becomes the tallest person there; but it sounds odd to say that John becomes taller than the others present, or that they become shorter than John. By sudden relational becoming (SRB, for short), I mean the becoming of something in relation to the sudden occurrence of something else. It is rather surprising that (SRB) has not aroused grave misgivings. In presuming to close Gap I by means of an application of (SRB), most commentators on the passage are largely unaware of (SRB)'s failure to accommodate a basic intuition about relational becoming.

\subsection{A play of ambiguity?}

Beyond this, (Dice) manifests relationality within numerical invariance: it is adamant that the group of six dice is more numerous than the group of four dice and less numerous than the group of twelve. Thus, at another focal point, a further gap - let us call it Gap 2 unfolds between the comparative numerical constructions in (Dice) and the question at I54c8-9 taken at face-value, i.e. (Q154c8-9), which is unconcerned with comparative numerosities. Call this reading the intrinsic view.

I7 The fact that 6 is the harmonic mean between the two extremes 4 and 12 does not seem to me to be essential to (Dice)'s central thrust. Like many other mathematical examples that Plato chooses in the dialogues, this numeric triplet is meant to be enjoyed by the mentally alert reader, so as to involve her more intensely. For a contrary view, see Brown (I969) who regards (Dice) in connection with Theaetetus' work on irrationals, and Desjardins (I99o) I8I-92. I have no space to go into the details of these interpretations. 
Gap 2 may induce the commentator to transmit the relational pattern of (Dice) to the subsequent question by supplementing 'larger or more numerous' in (Q154c8-9) with a 'than' clause. Let us call this reading the relational view:

$\left(\right.$ Q154c8-9) ${ }^{\mathrm{r}}$ : is there any way in which something can become larger or more numerous than something else, other than by undergoing increase ${ }^{18}$

A corollary of the relational view is that Plato licenses his audience to regard (QI54c8-9) as an ambiguous question. Perhaps - as has frequently been supposed - the ambiguity in (QI54c8-9) should be understood as the first of a series of other intentional ambiguities working subtly in the whole stretch of text (see subsection 5.2). Admittedly, it seems circular to maintain that the demand for disambiguation fails to do justice to the facevalue of the question raised at $154 \mathrm{c} 8-9$, for it is precisely this face-value reading that is challenged by (QI54c8-9) ${ }^{\mathrm{r}}$.

However, I hold the intrinsic view, and thus maintain that the focus on the intrinsic/ relational ambiguity is misleading for the assessment of the passage. The matter is to be settled by considering the respondent's reactions to the two candidates (Q154c8-9) and (QI54c8-9) $)^{\mathrm{r}}$. The answer to (QI54c8-9) branches out into these alternatives:

(N-A) There is no way in which something can become larger or more numerous (than it was before), other than by undergoing increase.

(P-A) There is a way in which something can become larger or more numerous (than it was before) other than by undergoing increase.

The answer to (QI54c8-9) ${ }^{\mathrm{r}}$ instead branches out into:

$(\mathrm{N}-\mathrm{A})^{\mathrm{r}}$ There is no way in which something can become larger or more numerous than something else, other than by undergoing increase.

$(\mathrm{P}-\mathrm{A})^{\mathrm{r}}$ There is a way in which something can become larger or more numerous than something else, other than by undergoing increase.

The first point I wish to make is just that (QI54c8-9) ${ }^{r}$ is philosophically unimpressive. But it is not so because 'it is natural to answer negatively', as Job van Eck thinks. ${ }^{19}$ On the contrary, its answer is obviously affirmative, for both the Protagorean and the non-Protagorean. It is indeed easy to imagine the case in which the subtraction of three dice from a group $G$ of six causes a group $G^{\prime}$ of four dice to become more numerous than $G$. According to van Eck, the answer $(\mathrm{N}-\mathrm{A})^{\mathrm{r}}$ is warranted by the fact that 'the sentence " $\mathrm{x}$ becomes more/larger

I8 See, e.g., Polansky (I992) 93 and van Eck (2009) 2II-I2.

I9 van Eck (2009) 2 II. 
than $y$ " suggests that $x$ is the subject of the change involved but in the case of six dice $x$ does not undergo the change itself. ${ }^{20}$ The second part of the remark will be discussed in section 3, where I will argue that (Dice) does not require us to endorse the conclusion that the six dice do not change. As for the first part, I do not see clear reasons for assuming that the sentence ' $x$ becomes more/larger than $y$ ' should invite us to exempt $y$ from change. As a matter of fact, such an assumption is challenged by real-life situations. For example, when $x$ and $y$ vary over football teams and we say that during a match $x$ gains a numerical superiority over $y$, the most immediate explanation is that the superiority of $x$ is the effect of the changed numerical status of $y$ (someone from this team has been sent off). In sum, since the subtraction case is far from being sui generis, but is at the root of our conception of relational quantitative becoming, if the first half of Theaetetus' answer were $(\mathrm{N}-\mathrm{A})^{\mathrm{r}}$, then it would be irredeemably false.

Van Eck argues further:

with a view to the example he answers positively because he is afraid of committing a contradiction. Since what he would contradict is that the dice in the example have become 'more than the four', he must take the phrase 'larger or more numerous' in the general sense of 'larger or more numerous than anything' (than itself or something else). ${ }^{2 I}$

Hence van Eck's account leaves us with the special problem that we mentioned above. The 'contradiction' is avoidable only by resort to (SRB): the six dice have become more than the four dice springing from nowhere. To sum up so far: the first and negative half of Theaetetus' alleged response, $(\mathrm{N}-\mathrm{A})^{\mathrm{r}}$, constitutes a simply flawed answer (for the subtraction case), whereas its second and positive half, $(\mathrm{P}-\mathrm{A})^{r}$, does inadvertently correct the mistake by appealing to (SRB). In other words, the communication between (N-A) ${ }^{r}$ and (Q154c8-9) breaks down. The fact that these two horns diverge should alert us to the fact that the intended question is not (Q154c8-9) ${ }^{\mathrm{r}}$, but (Q154c8-9).

I believe that the two-part nature of Theaetetus' answer exemplifies a dialectical interplay. Accordingly, the connection of the answer to (Dice) is subtler than has been supposed. On a common line of interpretation followed by van Eck, Theaetetus' own ruminations on (Dice) propel him from the first half of the answer to the second. ${ }^{22}$ When he takes into account the example just illustrated by Socrates, he no longer entertains the thought of $(\mathrm{N}-\mathrm{A})\left(\mathrm{or}(\mathrm{N}-\mathrm{A})^{r}\right)$ but the thought of $(\mathrm{P}-\mathrm{A})$ ( or $\left.(\mathrm{P}-\mathrm{A})^{r}\right) .{ }^{23}$ Now, from what I have said so far, I concede that $(\mathrm{N}-\mathrm{A})$

20 van Eck (2009) 2I2.

$2 \mathrm{I}$

van Eck (2009) 2II-I2. There is a difficulty in the supposed 'general sense' of 'larger or more numerous than anything'. If it were true that 'anything' in such a phrase included 'itself, then (QI54c8-9) ${ }^{r}$ would automatically imply (QI54c8-9). The suspicion here is that such an inclusion is fundamentally foreign to the Greek mind, but it would take me too far from my present subject to pursue this point further.

22 See also Lee (2005) ror.

23 Scholars reach the conclusion that (Dice) pushes in the direction of the second half of Theaetetus' answer by assuming a referential link between ' $\pi \rho \cos _{\varepsilon} \rho \alpha \nu$ question' at $\mathrm{I}_{54} \mathrm{~d} 2$ ('but if I answer with a view to the one 
cannot be conceived of as a direct reaction to (Dice). Otherwise, Theaetetus would assert $(\mathrm{N}-\mathrm{A})$ because he understands (Dice) either as describing some groups of objects that under numerical invariance can become greater/lesser only relatively, or as describing some groups of objects that under numerical invariance can be greater/lesser only relatively. In the first case, (SRB) is again in force; in the second, Gap I (see section I.3). My warning is against the supposed impact of (Dice) on the boy's reply after the first half.

In my view, the effect of (Dice) turns out to be retrospective rather than prospective. The idea is not that (Dice) argues for (P-A), but that (P-A) creates the logical space for activating (Dice) as its field of operation. Theaetetus' answer matches an ordered pair given by a general thesis, (N-A), trivially true according to a common view of quantitative change, and its denial, (P-A), which confers on (Dice) the status of a counterexample to (N-A): there is a way in which something (e.g., a group of dice) can become larger or more numerous (than it was before) other than by undergoing increase. This automatically offers the simplest explanation for the ordering of the two horns of the answer. Moreover, in section 4, in contrast with most commentators, I explore evidence and reasons for revising Theaetetus' own attitude towards (N-A) and (P-A). Pace McDowell, the boy's state of mind is not divided by 'two contradictory inclinations'. His answer to (Q154c8-9) is not: 'no and yes', but rather: 'no for me' and 'yes for Protagoras', where 'yes for Protagoras' is a marker for the underlying purpose of understanding the Protagorean doctrine. In short, (Dice) comes retrospectively to the fore as a Protagorean counterexample to (N-A).

\subsection{A fallacy secundum quid?}

Some commentators believe instead that (P-A) is the conclusion to which Theaetetus is drawn by a deviant conditional. Such a conditional could be written semi-formally as:

(Num) if at a time $t^{\prime}$ a group of (discrete) objects $G$ becomes more/less numerous than another group $G^{\prime}$, then $G$ becomes more/less numerous than it was at time $t<t^{\prime}$ (i.e., more/less numerous simpliciter). ${ }^{24}$

Again, the antecedent of (Num) takes (SRB) on board. But more to the point, it is odd to find Theaetetus committed to (Num) as a whole, since (Num) involves the fallacy a dicto secundum quid ad dictum simpliciter by shifting from a relational use of 'more/less numerous' to a non-relational one. Hence Theaetetus should be given low marks for ignoring Euthydemus, Plato's anti-eristic work, wherein this kind of blatant fallacy is described and

before') and (Dice). Yet this link receives no special encouragement from the text, clashing with the given that no question relative to (Dice) is left suspended a few lines earlier. The only question posed, about the numerical relations among the dice, anticipates and receives a negative answer. In section 4, I shall suggest what I believe is a more plausible hypothesis.

24 McDowell (1973) I34 and Cooper (1990) 29-30 are among the commentators who see at work a conditional like (Num). 
diagnosed (cf. 284d-e; 293c-d; 294b; 295b2-296d4; 297e-298c). ${ }^{25}$ But, of course, it is even more uncharitable to charge a brilliant mathematician able to generalise the proof of the irrationality of square roots of non-square integers ( $\mathrm{I}_{4} \mathrm{~d}_{3}-\mathrm{I}_{4} 8 \mathrm{~b}_{2}$ ) with embracing a disastrous conditional about numerosity like (Num). I am not referring only to the fact that the Platonic reader would hardly expect a mathematical mind to endorse the view that becoming more numerous simpliciter for a set of objects may be parasitic upon the set's relations to sets of objects distinct from itself. A further counter-indication is particularly pressing: if (Dice), by means of something objective such as the comparison of cardinalities of sets, promotes the first encounter between the Protagorean credo and the demands of the intersubjective activity of counting and measuring ('we can't allow the case to be differently described' (I54b4-5); cf. Euthyphr. 7b6-cI), then it would be incomprehensible for a mathematician to forfeit this chance. ${ }^{26}$

On the other hand, Theaetetus' endorsement of the (Platonic) wrong horn (P-A) coupled with (Num) implies that the sophist has conceptual resources for dispelling the boy's confusion. Nevertheless, we expect this solution to be explained by a feature that is specifically Protagorean, and there is nothing distinctively Protagorean in the manoeuvre of restoring appropriate qualifiers circumventing the fallacy a dicto secundum quid. And still worse, an explicit manoeuvre against the fallacy might be conceived of as an outcome inappropriate for a Protagorean: it cannot be part of a Protagorean agenda to offer a solution to (Num) capable of being objectively acknowledged as such.

\subsection{Simultaneity?}

There is a long tradition in the literature, going back to Lewis Campbell, of tracing here a relevant connection to Plato's analysis of comparative properties in the middle-period dialogues and especially in the Phaedo. ${ }^{27}$ Such properties are regarded as the most serious threat to the Principle of Opposites: 'the same thing will not do or suffer opposites

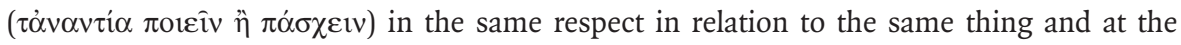
same time' (Rep. IV, 436b8-9; cf. Phaed. ro5a). In the Phaedo, Socrates explains the fact that Simmias is taller than Socrates but shorter than Phaedo by assigning to Simmias both tallness (in relation ( $\left.\pi \rho \rho_{\varsigma}\right)$ to Socrates) and shortness (in relation to Phaedo) (Io2b3I03a2; cf. also Rep. IV, 436e8-437a2; Charm. r68b; Soph. 255cI2-I3). A discussion of Plato's treatment of comparative properties would take us too far afield. However, all that needs to be granted for my purpose is that Plato's concern over comparative properties arises from their simultaneous occurrence. More generally, in order to challenge the Principle of

25 In view of what I will argue, let me register one caveat. I am not claiming that (P-A) constitutes an irrational stance unqualifiedly: as I will show, it is not so for the Protagorean, given a set of assumptions endorsed. Rather, it is irrational for the non-Protagorean.

26 Haring has rightly insisted upon this encounter, recalling also the fact that measurement is not part of Protagorean instruction (cf. Prot. 318e): Haring (I992) 527.

27 Actually, Campbell (I86I) 47 in tracing this connection is more prudent than other commentators, e.g., Ross (I953) I0o, who writes that at I54C7-I55cio Plato 'lights on the same problem' as in Phaed. I02. 
Opposites any putative counterexample must involve the relation of simultaneity (see, for instance, Rep. IV, 436c9-10; 436d4-5).

In the Theaetetus the notion of simultaneity is at the core of the first example elucidating Protagoras' Measure Doctrine: the same wind is cold for one perceiver and warm for another (I52bI-6). So the thing $x$ which appears $F$ in a context involving an observer may be simultaneously not-F in a context involving another observer. But the context-dependency of perceptual properties prevents the sophist from jumping to the conclusion that $x$ is both $\mathrm{F}$ and not-F. Now, with (Dice), the discussion turns to comparative properties, but the example does not tackle their simultaneous occurrence. An array of six dice is not brought into comparison at once with two arrays of dice, with the result that six dice are simultaneously more than the four and fewer than the twelve. On the contrary, the actual example exhibits two comparisons, the first generated once four dice are placed next to six, the second once twelve dice are placed next to the six. In sum, to instantiate a case of the type: 'Simmias is taller than Socrates but shorter than Phaedo', the example should have a pattern of this kind:

Take (a group of) four dice and (a group of) twelve dice. If you put six dice besides them, we say that the six are more than the four and fewer than the twelve. ${ }^{28}$

On the other hand, nothing in the description of (Dice) induces us to concatenate the numerical relations among the dice (and, in the end, the question at $154 \mathrm{c} 8-9$ focuses exclusively on something's becoming more numerous). The presence in (Dice) of the pair of particles $\mu \dot{\varepsilon} v \ldots \delta \dot{\varepsilon} v$ can be stressed as follows:

Take six dice. If you put four besides them, we say that they are more than the four; while if you put twelve beside them, we say they are fewer than the twelve.

But this does not mean that (Dice) points out that six dice are more than four but less than twelve. Pace Russell and many others readers, there is no 'but' between the two numerical relations. There is a 'but' between two distinct juxtapositions.

\section{2. $154 b$ again}

\subsection{Is Cambridge change Abdera change?}

A more sophisticated vindication of (NC-I) consists in appealing to the distinction between 'real' and 'strict' Cambridge change, so as to make Plato's Protagoras a proto-Geachean. ${ }^{29}$

28 And perhaps, in order for the harmonic mean to contribute to the structure of the example, one should have the further condition that the six dice are put between the two groups of dice (see n. I7).

29 An object undergoes a Cambridge change when a proposition about it changes in truth-value: both Theaetetus and Socrates underwent a Cambridge change when Theaetetus grew taller than Socrates. But the change in Theaetetus was a real one, whereas the change in Socrates was a strict Cambridge change, i.e. Socrates has undergone a change 
As van Eck has argued, indeed, the case of $154 \mathrm{~b}$ comes to delineate a strict Cambridge change, namely 'it is about something becoming different without undergoing any change itself. ${ }^{30}$ To drive the point home, van Eck draws a distinction between two ways of becoming different in the critical passage: the dependent (on a particular individual) and the independent one, which corresponds to the non-Protagorean, common-sensical, conception of change. A bit more formally sentences like: ' $x$ becomes dep $F$ ' and ' $x$ becomes $F$ ' stand for ' $x$ becomes $F$ to an observer' and ' $x$ changes from not- $F$ to $F$ ', respectively. ${ }^{3 \mathrm{I}}$ With this distinction in mind the segment at $154 \mathrm{bI}-3$ would run something like this:

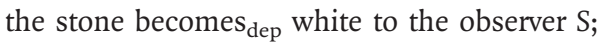

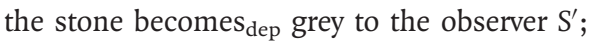

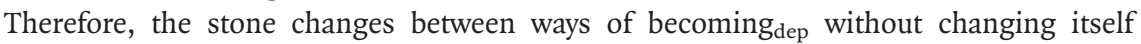
(i.e. without changing from white to grey).

It seems to me that there are two main difficulties with van Eck's account, the first technical and the second more general. The first is that, on his reading, there actually exist not two but three sorts of change: the stone's change between ways of becoming ${ }_{\text {dep }}$, indeed, cannot be identified with either a change dependent on a particular observer or an intrinsic change from being not- $\mathrm{F}$ to being $\mathrm{F}$. But this is not the kind of change that can occupy a relevant Protagorean niche, for the simple reason that no actual perceptual meeting is capable of

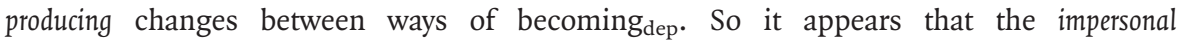

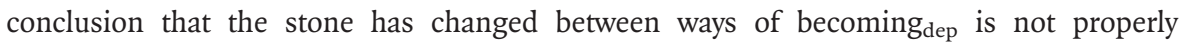
Protagorean and thus cannot figure within a metaphysical argument engineered by Plato as Protagorean.

The second difficulty is a refinement of the explanatory objection to (NC-I) I referred to in subsection I.3. That is to say, the Cambridge change account of $154 \mathrm{bI}-3$ entails that the

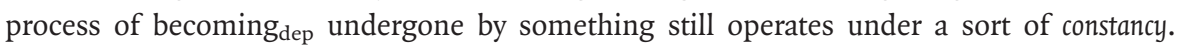
But this does not feel like the right consequence here. Paradoxically, indeed, this way of interpreting I54 b construes the locus as somewhat reminiscent of Aristotle's gambit against the Heracliteans (Metaph. IV, IoIo, aI5-20): it is because a thing $x$ to some extent remains constant through time under distinct perceptions that it is possible to say that exactly $x$ becomes $_{\text {dep }}, F, F^{\prime}, F^{\prime \prime}, \ldots$, across different perceptions or meetings. So Plato's Protagorean represents two observers having not just two different perceptions, but two different perceptions of the same thing, with the result that the very same thing is not large or white or hot. However, for the sophist not only is the idea of the lifespan of objects wholly beside the point, but their ensuing referential stability fails to cohere with the

in his relation to Theaetetus. See Geach (I969) 7I-2. \$442 of Russell's Principles of mathematics is the modern locus classicus for this conception.

30 van Eck (2009) 213 .

3I van Eck (2009) 239. 
referential emptiness that constitutes the first damaging consequence of the extreme doctrine of the hyper-flux in the course of its final refutation (I82d6-7):

How could it be, Socrates? [scil. to refer to any colour in such a way as to be speaking of it rightly]. Indeed, how could it be possible to do so with any other thing of that kind, if it's always slipping away while one is speaking; as it must be, given that it's in

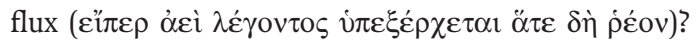

\subsection{Another reading}

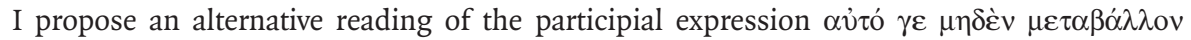
inside the counterfactual at $154 \mathrm{bI}-3$. This reading retains the official platform of Heracliteanism, while referring to the prerogative of Protagorean becoming. It seems to me that the whole counterfactual projects the idea that things that become different when they appear different are not physically modified by the encounter. So, such a counterfactual should be read as:

I54bI-3: if the object $x$ had been large, white, or hot, then $x$ would never have become different (by coming into contact with people), without a correlative physical alteration.

Hence: it is not that $x$ becomes different without itself changing, as (NC-I) and the Cambridge change view assume. In fact, since $x$ becomes different by coming into contact with people, $x$ ipso facto changes; yet the coda of the counterfactual at I54bI-3 supposes that this change remains circumscribed to the encounter. What, then, accounts for the string $\alpha$ $\tau$ ó $\gamma \varepsilon \mu \eta \delta \dot{\varepsilon} v \mu \varepsilon \tau \alpha \beta \alpha \dot{\alpha} \lambda \lambda o v$ ? So far we have been instructed that each perceptual property arises in a way that makes it peculiar ('ioiov) (I54a2) for each percipient; then Socrates has insisted via (CI) and ( 2 2) upon the individual and vanishing character of appearance; next he has made use of the claim $\left(\mathrm{CI}^{\prime}\right)$ suggesting a causal route from the interaction of an external object $x$ with different persons to its becoming different. Finally, the specification $\alpha$ $\tau$ ó $\gamma \varepsilon \mu \eta \delta \dot{\varepsilon} v \mu \varepsilon \tau \alpha \beta \dot{\alpha} \lambda \lambda o v$, by pointing out that $x$ 's becoming leaves no material trace upon $x$, introduces to the stage the privacy of becoming. Note that such a specification establishes something stronger than the pair (CI) and (C2): if a perceptual encounter $e$ would alter the physical career of $x$, then the diversity of $x$ 's appearance in another perceptual meeting would be related to the effect of $e$.

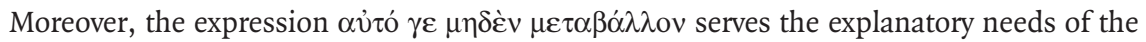
counterfactual at I54 bi-3. For the Protagorean the intended explanans for the explanandum that a thing $x$ is not large or white or hot is not just the fact that $x$ becomes small or black or cold in a perceptual encounter with another individual, but rather the fact that $x$ 's becoming small or black or cold in these encounters is a phenomenon accessible only from a particular experiential point of view to the extent that $x$ survives physically unscathed for 
other encounters. In a nutshell, if $x$ had been large or white or hot, it would never have become different privately. ${ }^{32}$

Hence the rendering I am promoting has the benefit of unravelling the contribution of

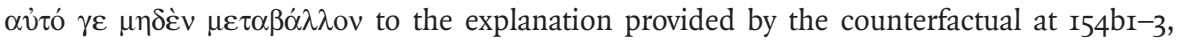
so that the explanatory objection lodged against (NC-I) fails to apply. Furthermore, by saying that the object $x$ becomes different without the slightest effect on its physical course, the counterfactual $154 \mathrm{bI}-3$ does not involve a departure from the basic tenet of the flux doctrine, for it does not commit the Protagorean to denying that $x$ undergoes change. What the sophist claims is that, insofar as it is private, the change of $x$ via appearance/perception (I52CI) lies wholly insulated from the appearance of $x$ to other perceiving subjects.

This is not the whole Protagorean/Heraclitean story, however. For Plato's Protagoras embarks on the project of bracketing appearances. Why not suppose that the very encounter between two distinct things makes them become different? Since at least one spectator is needed, such an encounter with a spectator is called comparison. The $\sigma \mu \mathrm{u} \rho \mathrm{o} v$ $\pi \alpha \rho \alpha \dot{\delta \varepsilon} \gamma \mu \alpha$ launches precisely this second phase.

\section{Protagorean comparisons}

\subsection{The new thesis}

To grasp the full import of the ensuing phase, it is important to realise that the introduction to the stage of the notion of becoming bigger or more numerous poses no fresh problems for the Protagorean theory, nor does it create a new level of complication. From the vantage point of Protagorean appearance, indeed, a multitude's becoming bigger, as distinct from a thing's becoming big, is not a more difficult phenomenon to put across. After all it is part of the Protagorean doctrine that numerosity cannot exist aside from a (private) perception of it: since there is no misperception, there is no miscounting either. Imagine a group of $n$ dice to which a person by counting assigns $n$ elements at one time, $\mathfrak{n}+\mathrm{I}$ elements at a successive time: that group of dice becomes more numerous, but it cannot be said to have increased in number during that interval.

Once it is clear that the phenomenon of something's becoming more numerous is already accountable in terms of appearance, it becomes all the more revealing that (Dice) marks a step forward in Protagorean theory not despite the fact that but because it is not intended to be a case of conflicting appearances, not even of a more sophisticated variety. ${ }^{33}$ First and foremost, Socrates makes no statement to the effect that the group of six dice appears

32 After all, my reading amounts to arguing that $\mu \varepsilon \tau \alpha \beta \alpha \dot{\alpha} \lambda \lambda \omega$ must be seen as attuned to $\pi$ ó $\sigma \omega \omega$, which is employed twice within the apodosis of the second counterfactual at $154 b_{3}-6$. Note that its first occurrence is when Socrates

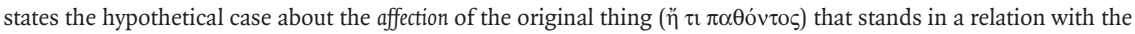
measuring one. If, as it is natural to suppose, such a case covers the opposite scenario of the first apodosis, then the very presence of this verb supports our reading. 
more than the four dice and less than the twelve. He says that the group of six dice is more than the four and that it is less than the twelve. Second, (Dice) copes with the notion of quantitative comparison between sets of physical individuals (aggregates); and since the two comparisons in (Dice) are not simultaneous, and the text does not require the concatenation of the resulting numerical relations, there is no room for conflict.

My reading of the conditional behind (P-A) removes the antecedent of (Num), while keeping its consequent, so that the conditional introduces a new route from quantitative comparison of aggregates to their becoming more/less numerous (simpliciter):

(Com) if at a time $t^{\prime}$ a group of (discrete) objects $G$ is compared to another group $G^{\prime}$ of smaller/bigger cardinality, then $G$ becomes more/less numerous than it was at time $t<t^{\prime} .34$

Comparison serves two main functions. One bears directly on the actualisation of latencies, for comparison produces a new kind of encounter between different comparable things. And the other indirectly bears on the surveyability of the encounter itself, since such an encounter to be recorded must not only be done but be seen to be done.

According to this perspective, (Dice) appears on the scene to merge the two distinct modes of becoming - becoming-via-appearance and becoming-via-comparison - into a uniform picture. And therefore when Socrates, on behalf of the Protagorean, raises Q154c8-9, Theaetetus is ready to interpret him as asking: is there any way in which an aggregate can become bigger than it was before without being 'affected' by fresh additions? From the Protagorean standpoint, such a question acts as a new cutting edge: just as something can become small, black, cold by interaction with an observer while it is not (materially) affected, so by interaction/juxtaposition with something else, a given aggregate can become more (or less) numerous than it was while its cardinality is not increased (or decreased).

If what I have been arguing is correct, then much current discussion of the passage is misguided. Various commentators indeed relate (NC-I) with (Dice) by assuming that (Dice) implements a situation where something (i.e. six dice) does not change while becoming different. On inspection, however, this way of assessing (Dice) lies in a distortion of the text. It is uncontroversial that (Dice) talks about a group of six dice which does not increase or decrease when the two comparisons are made; nevertheless (Dice) remains perfectly neutral on the question of whether that group remains unchanged or not. Hence, while in (Dice) that collection of individuals is described as remaining numerically stable, the very possibility of its becoming bigger simpliciter without gaining

34 This conditional forms the basis of my reappraisal of Bluck's interpretation. He writes that six dice and Socrates 'do undergo change of a sort, though the six dice are not increased or decreased in number, nor Socrates in stature; they are all 'affected' (the word used at $154 \mathrm{~b}$ was $\pi \alpha \theta$ óv) in different ways when the different comparisons are made, and that is what causes them to become 'different' - more, fewer, or shorter, as the case may be' Bluck (rg6r) 8 (emphasis added). 
(or losing) elements is the bone of contention between the Protagorean and the nonProtagorean which Q154c8-9 brings into light.

Finally, let us examine the role of the pivotal verb $\pi \rho \circ \sigma \phi \varepsilon \rho \omega$ in (Dice). This verb, in the sense of 'putting beside', connotes an act of juxtaposition, bringing two groups of dice in mutual relation (cf. the reciprocity of $\pi \rho \grave{s}_{\varsigma} \not \alpha \lambda \lambda \eta \lambda \alpha$ at $\mathrm{I}_{52 \mathrm{~d}}$ ). The pairs of conditional sentences ( $\not 2 v$... غ̇óv) introduce each comparison as the result of a physical action. But why? After all a comparison is also attainable by a case in which at least two different collections of objects lie from the outset on a surface. Very briefly, I propose two simple answers to explain the purpose of juxtaposition in (Dice). First, it is important that the term $\pi \rho о \sigma \phi \varepsilon ́ \rho \omega$ be given a quasi-technical interpretation to allow it to express the sort of random encounter previously denoted by the verbs $\pi \rho \circ \sigma \pi i \tau \omega \omega$ (I54b2) and $\pi \rho \circ \sigma \varepsilon \dot{\rho} \chi 0 \mu \alpha \mathrm{l}$ (b5). Second, the juxtaposition places human constraints on the genesis of quantitative comparisons. Comparisons/focalisations remain internal to the arbitrary activity of selecting what to compare with what, from a superabundant array of possibilities in a network of linkages. Yet (Dice) also makes it clear that once a subjective choice is made by an agent, nobody can evade its mathematical outcome. Let us now consider the prospect of this outcome.

\subsection{Correctness, after all}

In effect no modern commentator, to the best of my knowledge, has bothered to scrutinise the correctness of the comparisons in (Dice) as a special philosophical message on Plato's part. This omission is all the more striking in the face of his insistence on a resulting agreement. First, this agreement is epitomised in the very precision of the mathematical language of means describing the arithmetical relations between the groups of dice. Second, this description corresponds to Socrates' shift from the singular action verb for Theaetetus' fictive juxtaposition to the plural ( $\phi \alpha \mu \varepsilon \dot{v})$ verb of saying. Finally, the closing rhetorical question stresses the inconceivability of an alternative to this arithmetical state of affairs.

Now, it is hardly coincidental that Socrates focuses on increase and diminution, for of all kinds of change, changes in quantity (cf. Aristotle, Cat. I4, I5aI4-I5; Phys. V, 226a30-32) are obviously the most congenial to ascertaining an overtly realised or unrealised alteration of state. Nevertheless, since a (correct) quantitative comparison marks the intersection between a subjective choice and a shareable outcome, it is tempting to see an anti-Protagorean manoeuvre on Plato's part involved here. Of course, in order not to beg the major question against Protagoreanism, this move cannot depend on the consideration that it is because it is true that 6 is more than 4 that the group of six dice becomes more numerous when it is compared to a group of four. To this move, on the other hand, the Protagorean might reply that he agrees that 6 is more than 4 without agreeing that the belief that 6 is more than 4 is true simpliciter. ${ }^{35}$ Rather, on my view, the indirect line of

35 I take Protagoras to hold the view that the beliefs of two individuals can share contents, while remaining private. It is precisely because the Protagorean cannot deny the phenomenon of human agreement that in a subsequent 
attack trades on the interworking between (N-A) and (P-A). It is not just that for the Protagorean an agreement on numerical relations licenses his access to the very notion of increasing upon which both $(\mathrm{N}-\mathrm{A})$ and $(\mathrm{P}-\mathrm{A})$ rest. It is rather that $(\mathrm{P}-\mathrm{A})$ can be a reaction to $(\mathrm{N}-\mathrm{A})$ only through a convergence of mathematical points of view, no matter if for the Protagorean arithmetical truth remains individual. In other words, the moral we are meant to draw is not just that for the Protagorean increasing remains a sufficient though not necessary condition for something's becoming more numerous. The moral here is that he cannot preserve the very intelligibility of this view without reliance on a common view of arithmetical relations. The upshot, then, is not the objectivity of arithmetic, but its degree of continuity inside and outside the Protagorean world.

\section{Theaetetus' split answer}

\subsection{Two questions}

The difficulty of approaching Theaetetus' answer at I54CIO- $\mathrm{d}_{2}$ stems in part from the failure to acknowledge one central feature of (Q154c8-9), namely that it does not belong, stricto sensu, to Socrates. Indeed, Socrates imagines (Q154c8-9) as a question that could have been posed by Protagoras: 'suppose that Protagoras, or anyone else, asks you...' (öv $\sigma \varepsilon$

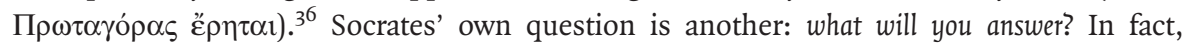
Theaetetus' reply activates two different conditional levels ( $\underline{\dot{\varepsilon} \grave{\alpha} v} . . . \underline{\varepsilon} \dot{\alpha} \mathrm{v})$ corresponding to the two different questions (I54cro-d2):

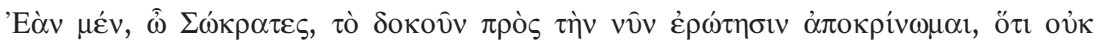

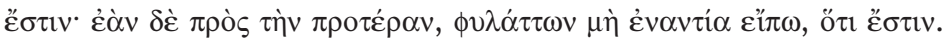

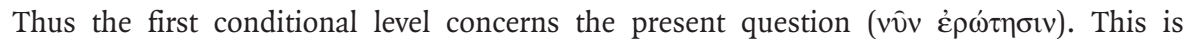
Socrates' question: 'what will you answer?', encouraging Theaetetus to voice his own

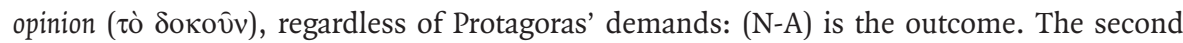
conditional level concerns instead a $\pi \rho 0 \tau \varepsilon \rho \alpha v$ question, which, I surmise, refers to Protagoras' hypothetical question. Now Theaetetus assumes that he is required to produce the answer from Protagoras' point of view: (P-A) is the outcome.

Admittedly, the completion of the elliptical conditional at $154 \mathrm{dI}-2$ makes all the difference to the evaluation of the whole answer. Like Cornford and McDowell, I confine the presence of a doxastic attitude to the first part of the answer. So I judge the second

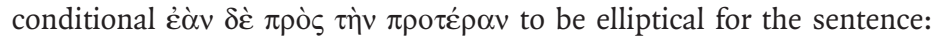

(eI) if [I answer] with a view to the one before [...].

phase of the discussion Socrates comes to raise the hypothesis, against the Protagorean yet quite unSocratic (e.g., cf. Lach. I84e8-9), that the truth of beliefs grows in proportion to their communitarian pervasiveness (I7raI-3).

36 I interpret 'or anyone else' ( $\left.\dddot{\eta} \tau \iota \varsigma \ddot{\alpha} \lambda \lambda \lambda_{0}\right)$ ) as having the same extension as 'everyone who undertakes to agree with him [scil. Protagoras]' at $154 \mathrm{~b} 8$ (cf. also $152 \mathrm{e} 8-9$ and $\mathrm{I}_{62} \mathrm{~d}_{4}-5$ ). 
rather than being elliptical for:

(e2) 'If [I answer what I think] with a view to the one before [...].

Indeed (e2) strikes me as implausible. First, let us concede that the whole answer is composed of two opposite $\delta$ ó $\xi \alpha$. Now, the very tension between its two halves would be indicative of a mind which has not yet decided between two incompatible alternatives (I89e6-19oa3). But such doxastic vacillation would conflict with the subsequent characterisation of the $\delta \xi^{\prime} \alpha$ as the cognitive state in which the mind is 'no longer divided, but says one single thing' (190a3-4). Second, the weak spot of (e2) lies in its failure to make sense of the phantom of contradiction evoked by Theaetetus at $154 \mathrm{~d} 2$

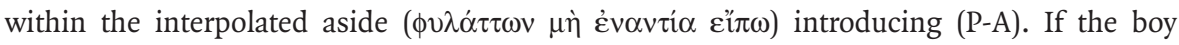
really thinks both that (N-A) and that (P-A), then there is no way to evade the contradiction.

Rather it seems to me that the logical warning that Theaetetus gives himself serves to reinforce the doxastic asymmetry between the two halves of the answer. Theaetetus' second-order thought can be equated with the converse of the Socratic principle that it is impossible, in full awareness, to hold contradictory beliefs (Rep. X, 602e8-9). Namely, the proposition: 'if I hold contradictory beliefs, I do not hold them in full awareness' entails: 'if I realise that I believe a contradiction, then I no longer believe one of the two contradictory beliefs'. In practice, such self-warning signals that Theaetetus judges himself safe against contradiction. This entails the exclusion of an intervening change of mind.

It is not for nothing that in reply Socrates hastens to shift the focus to the sole conjunct (P-A), instead of considering the two غ́v $\alpha v \tau^{i} \alpha$ adumbrated by his interlocutor ( $\mathrm{I}_{54} \mathrm{~d}_{5}-6$ ):

Good, by Hera! ${ }^{37}$ Excellent, my friend! Still, if you answer that there is, it looks as if it'll turn out like that tag from Euripides: we'll find that your tongue is irrefutable

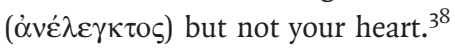

Although most commentators tend to overlook the (mis)quotation from Hippolytus, I want to suggest that it has a precise function. In fact, Socrates is concerned to reaffirm the point that Theaetetus is not refutable when he utters (P-A) because of the lack of endorsement of (P-A). And because he is not refutable answering (P-A), he cannot be open to the charge of falling into contradiction by answering both (N-A) and (P-A).

37 In the dialogues, Socrates' oath to Hera comes to connote approval with a sting of irony (cf. Apology 24e; Hi. Min. $287 \mathrm{a}$; Gorg. 449d). Note incidentally that at 15227 Socrates quotes from book I4 of the Iliad $(201,302)$ the words of a lying Hera.

38 In the Hippolytus the issue is not one of logic, but of ethics. Once the Nurse exhorts Hippolytus not to break his

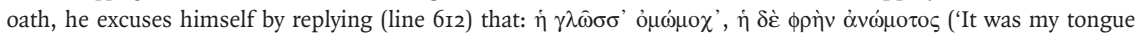
that swore it, not my mind.') 


\subsection{An internal thread}

There is another piece of evidence that (P-A) indicates the effort needed to discern the contents of Protagoras' mind. This line of evidence is discernible in Protagoras' second speech of defence, wherein the sophist makes a disclaimer of responsibility for Theaetetus' exercises in impersonation. These exercises have a limited effectiveness since

when it's something of mine that you're investigating by putting questions, I'm refuted if the person who had the question put to him trips up because of giving

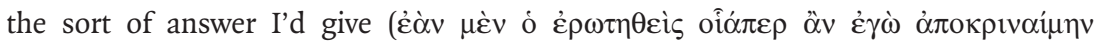

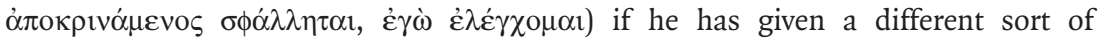
answer, he's the one who is refuted - the person who had the question put to him $\left(\right.$ (I66a6-bi). ${ }^{39}$

Protagoras' words bear a striking similarity to the claim made by Socrates citing Euripides at I54d3-6. In the passage above the sophist retorts that he cannot be refuted since his own state of mind is not represented by Theaetetus' vicarious pronouncements. With the roles reversed this is exactly what we see happen with Theaetetus' second horn (P-A): the boy is not refutable since (a part of) his answer does not correspond to his own thought but to Protagoras'.

\section{Apparitions, ambiguity, consistency}

\subsection{Three shared assumptions}

At this stage of the conversation Socrates speaks of three apparitions ( $\phi \dot{\alpha} \sigma \mu \alpha \tau \alpha$ ), using a rather rare word (seven occurrences in all) in the Platonic corpus. According to McDowell, such a lexical choice embodies the fact that each фó $\sigma \mu \alpha$ 'states something which appears to be the case' (emphasis added).$^{40}$ Yet it seems to me that the noun refers not so much to an alethic appearance as to a cognitive one. The stress, indeed, is upon the fact that some thoughts are now occurrent insofar as the discussion has made them arrive at the surface of consciousness. Such an emergence dovetails with the spatial frame of pronominal reference: 'in us', 'into ourselves' (I55aI-2). At any rate, the enumerated $\phi \alpha ́ \sigma \mu \alpha \tau \alpha$ are the following:

$(\phi I)$ Nothing could ever become larger or smaller, either in size or in number, as long as it were equal to itself ( $\check{\omega} \omega \varsigma$ ǐ

39 On the same point cf. Aristotle, Top. VIII, 5, 159b27-35. The possibility of being refuted that Protagoras here grants was also implicit in his first and shorter speech of defence, when the sophist complains that 'there's absolutely no proof or necessity' in what his opponents say (162e4-5).

40 McDowell (1973) I33. 
(\$2) A thing to which nothing is added and from which nothing is taken away

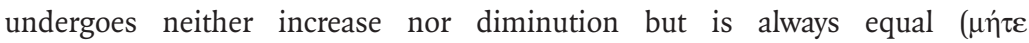

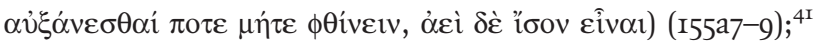

(\$3) It is impossible that a thing should be, subsequently, what it was not before,

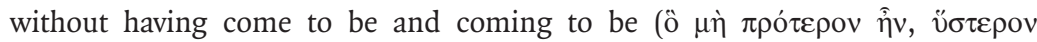

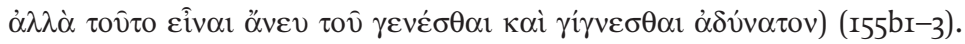

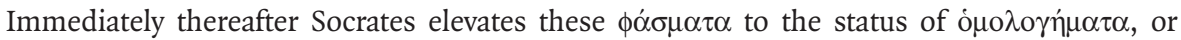

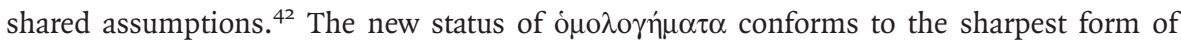
awareness, as if the $\phi \alpha \dot{\sigma} \sigma \mu \alpha \tau \alpha$ had become reflectively stable. More specifically, such an

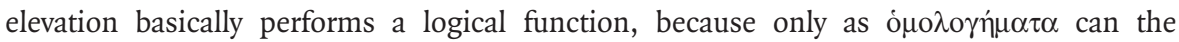
former apparitions play a constraining role of assumption in a step-by-step train of reasoning, going from one (occurrent) mental state to another. From a logical point of view, the three o $\mu$ o $\lambda о \gamma \eta \dot{\eta} \mu \alpha \alpha$ do not overlap. They appear in ascending order of ambitiousness. The first two assumptions sound like the voice of common sense. Crucially, they should also be understood to display an antipathetic attitude towards the Heraclitean theory, because they grant the possibility that things stay unchanged. While assumption $\varphi \mathrm{I}$ dictates when it is possible to affirm the quantitative change of something, assumption $\varphi 2$ subordinates quantitative stability to the lack of quantitative change. Notable about $\varphi 2$ is that it focuses on something more akin to inertia, as stressed by the strongest of temporal adverbs, i.e. $\dot{\alpha} \varepsilon$ í, with a normative vein: every thing will continue to remain equal to itself, unless acted upon by whatever addition or subtraction of matter. Finally, the last assumption $\varphi_{3}$ remains distinct among the three. First, it claims to be universal in its application by incorporating all forms of change. Second, it involves an interval of time in which change intervenes: a thing's change may be regarded as a path consisting of a distance between qualities lost and acquired.

\subsection{Against Hackforth's interpretation}

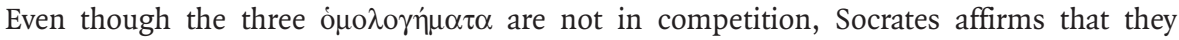

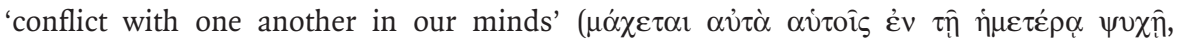
I55b4-5) when one talks about the situation of the dice as well as about Socrates' size

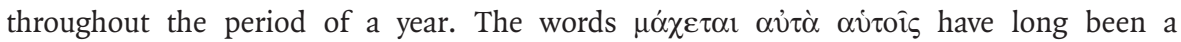
concern among modern commentators. In the I950s, Reginald Hackforth glossed these words as meaning that 'each of the three admissions fights against itself. He claimed that the three statements have been ambiguously formulated such that each of them 'apparently involves its own denial: it finds its enemy within itself, so to say, by giving

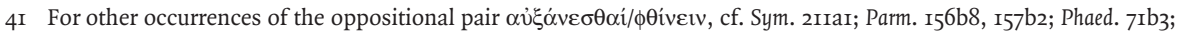
Ti. 8Ib5; Epinom. 979a3.

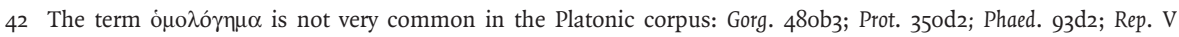
$462 e 5$. 
rise to its own contradiction'. ${ }^{43}$ To put it simply: the truth-value of each o $\mu$ o $\lambda$ ó $\gamma \mu \alpha$ varies as we understand each statement to carry an intrinsic or relational sense. In short, the latter sense makes the three assumptions individually false:

$(\varphi \mathrm{I})^{r}$ Nothing could ever become larger or smaller relative to something else, either in size or in number, as long as it were equal to itself;

$\left(\varphi_{2}\right)^{r}$ A thing to which nothing is added and from which nothing is taken away undergoes neither increase nor diminution relative to something else, but is always equal;

$\left(\varphi_{3}\right)^{r}$ It is impossible that a thing in relation to something else should be, later on, what it was not before, without having come to be and coming to be.

I offer a quick counter-argument against Hackforth's interpretation. Hackforth's own

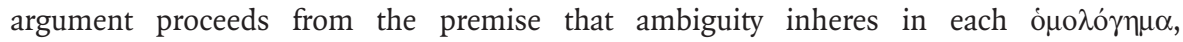
vacillating between an intrinsic and relational dimension, to the conclusion that in each statement one dimension is meant to war against its counterpart. But one can challenge the premise of such an argument which essentially amounts to discounting the elevation

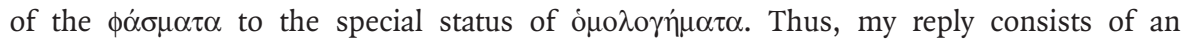
argument to the effect that 'ambiguous o $\mu$ o $\lambda$ ó $\gamma \mu \alpha$ ' is a contradictio in adjecto: if ambiguity arises, it does so because each фó $\sigma \mu \alpha$ might have an intrinsic dimension and might have a relational dimension, but since each o $\mu$ o $\lambda$ ó $\gamma \eta \alpha$ is the upshot of a choice between the two ways in which each $\phi \alpha \sigma \mu \alpha$ is ambiguous, it follows that the o $\mu$ o $\lambda \sigma \gamma \eta \dot{\eta} \alpha \tau \alpha$ themselves cannot be ambiguous.

Further evidence against Hackforth's reading can be gained from the occurrence of the

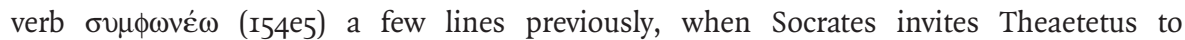
ascertain whether their thoughts $(\delta 1 \alpha v o o v ́ \mu \varepsilon \theta \alpha)$ harmonise with each another. Plato's appropriation of the musical term $\sigma u \mu \phi \omega v \varepsilon \dot{\varepsilon} \omega$ is well known to connote at least the idea of global consistency, leaving aside the question of whether the term has a meaning stronger than a logical relation. Plato uses the term to convey both negative consistency (one's beliefs do not undermine each other) - and positive (one's beliefs support each other). While it seems clear that it is negative consistency that is evoked in the critical passage, at any rate the very recourse to the term $\sigma \nu \mu \phi \omega v \varepsilon \dot{\omega}$ gives further warrant to the

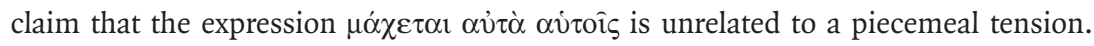

\section{The absurd and the wonder}

Now Socrates brings the tension within the o $\mu \mathrm{o} \lambda \mathrm{o} \gamma \mu \alpha \tau \alpha$ to its climax by introducing a new example ((Size), for short) concerning himself and Theaetetus. Let us subdivide the complex

43 Hackforth (I957) I30. Hackforth's reading is endorsed in Polansky (I992) i94. See also Kirwan, for whom $\phi \mathbf{I}$ 'is ambiguous, since its 'smaller' might be elliptical for 'smaller than something' or for 'smaller than it was' (Kirwan (I974) I28). 
passage at $155 \mathrm{~b} 6-\mathrm{c} 4$ into two adjacent segments, so as to disentangle the new example's import from the sibylline comment attached to it. The first segment is the following (I55b6-CI):

while being just this size, without growing or undergoing the opposite, I can within the space of a year be both larger than a young man like you, now, and smaller, later

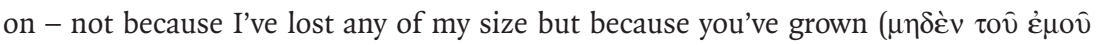

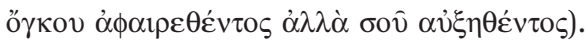

Though (Size) displays an obvious surface resemblance to (Dice), it also introduces a pair of new elements. First, (Size) involves a future temporal interval. This does mean (under the dramatic date of the dialogue) that the example projects Socrates forward into an unreal future. A more technical difference is that (Size) describes a relatum which is the subject of intrinsic change. In this regard, Theaetetus' growth in size in comparison with Socrates seems to exemplify the subcase in $\mathrm{I}_{54} \mathrm{~b}_{5}$ of the affection of a certain thing standing in relation to the one measuring ('[...] or the thing which came up against it has something happen to it').

The other segment of the passage reads as follows (I55C2-4):

Because that means I am, later on, what I wasn't before, though I haven't become it

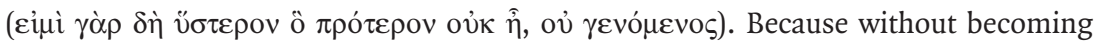
it's impossible to have become and, without losing anything of my size, I couldn't

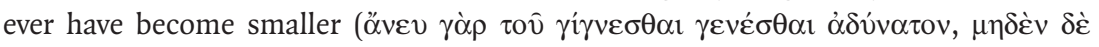

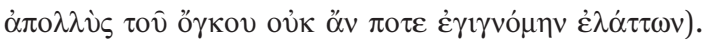

At this point a generalisation follows: the same line of reasoning can generate a myriad of other cases of this kind ( $155 \mathrm{C} 4-5)$.

Needless to say, the elliptical and attention-catching sentence

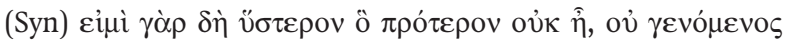

is pivotal to the understanding of our locus. In principle, there are $2^{2}$ ways of filling (Syn),

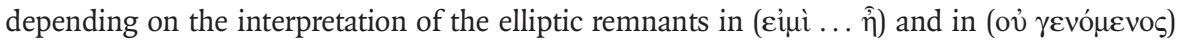
as relational or non-relational predicates. However, if we assume that the interpretation requires uniformity, the four possible accounts of (Syn) reduce to the following two:

(a) Socrates is, later on, smaller than Theaetetus, though he hasn't become smaller than Theaetetus.

(b) Socrates is, later on, smaller, though he hasn't become smaller.

I support reading (b). The strong reason for preferring (b) comes from the coda of the short explanatory chain ( $\mu \eta \delta \dot{\varepsilon} v \ldots . \dot{\varepsilon} \lambda \alpha \dot{\alpha} \tau \omega v$ : I55b8-cI) in the quoted passage: 'without losing 
anything of my size, I couldn't ever have become smaller'. This sentence is parallel to Theaetetus' answer (N-A). I am suggesting that we should understand (Syn) as an instance of the phenomenon known as synoeciosis, since (Syn) is designed to be the confluence of two incompatible claims corresponding to the poles of Theaetetus' answer to (QI54c8-9):

$(\mathrm{N}-\mathrm{A})^{\#}$ There is no way in which something can become smaller, other than by diminution. ${ }^{44}$

$(\mathrm{P}-\mathrm{A})^{\#}$ There is a way in which something can become smaller, other than by diminution. 45

Thus, to ensure a strong effect $(\mathrm{Syn})$ requires that both poles $(\mathrm{N}-\mathrm{A})^{\#}$ and $(\mathrm{P}-\mathrm{A})^{\#}$ be simultaneously maintained. Hence by the Protagorean horn (P-A) ${ }^{\#}$, Socrates is, later on, smaller than he was before, though, by the commonsensical horn $(\mathrm{N}-\mathrm{A})^{\#}$, he has not become smaller. As a result, my reading brings (Syn) into a subtler relation with the

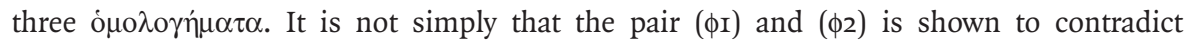
$(\phi 3)$. Rather, the assumptions $(\phi \mathrm{I})$ and $(\phi 2)$ underlying $(\mathrm{N}-\mathrm{A})^{\#}$ are necessary to frame the second and negative part of (Syn), which, as a whole, does in turn contradict the assumption $(\phi 3)$, while echoing its language.

Along this axis, (Syn) aspires to exemplifying one of the astonishing and ridiculous statements evoked at $154 \mathrm{~b} 6-7$ to which the non-Protagorean is committed. We should not think that the non-Protagorean is simply someone who declines to adopt the Protagorean account of change. He is rather the philosophical inquirer who attempts to 'follow up'

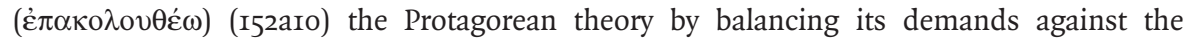
preservation of commonsensical beliefs. Viewed each from the other's standpoint, one conception of (quantitative) change undergenerates the possibilities which the other overgenerates. Yet the lesson to be drawn transcends the conclusion that some of the three ó $\mu$ о $о \gamma \eta \dot{\eta} \mu \alpha \alpha$ must be eliminated, with the sophist's injunction to override the assumptions ( $\left.\phi_{\mathrm{I}}\right)$ and $\left(\phi_{2}\right)$ in favour of ( $\left.\phi_{3}\right)$, which applies indifferently to anything capable of change. I claim that a more encompassing lesson concerns the change in one's own cognitive state by the assimilation of the contents of another thinker's mind: the

44 One might think that (Dice) lies on a discrete axis and (Size) on a continuous one, so that becoming different is an all-at-once event for the six dice, whereas it is a gradual one for Socrates' size. This view is not correct. Behind (P-A) ${ }^{\#}$ operates indeed such a conditional as:

$(\mathrm{Com})^{\#}$ if at a time $t^{\prime}$ a thing $x$ is compared in size to a thing $y$ bigger/smaller than $x$, then $x$ becomes smaller/ bigger than it was at time $t<t^{\prime}$.

So the becoming smaller of Socrates' size remains an all-at-once event depending on the activation of the comparison.

45 The radical unobservability of the change according to the Protagorean pair (P-A) and (P-A) ${ }^{\#}$ explains why Socrates

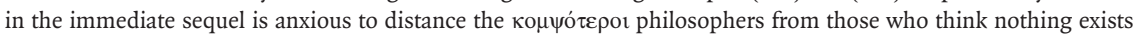
except 'what they can grasp firmly with their hands', and who 'don't admit doings, comings to be, or anything invisible, can count as real' (I55e4-6). 
inability to leave one's own conceptions out of the picture disables one from achieving intelligibility. The risk of this intellectual deadlock is, on the other hand, incumbent on the very purpose of this section of the dialogue: to bridge Theaetetus' definition of $\dot{\varepsilon} \pi \imath \tau \eta \dot{\mu \eta}$ as $\alpha i \sigma \vartheta \eta \sigma ı \varsigma$ and Protagoras' Measure Doctrine (the sophist 'put that same point in a different way', I52ai-2).

When Theaetetus replies to Socrates (I55c8-IO):

[...] it's quite extraordinary what wonder I feel $(\theta \alpha \nu \mu \alpha \dot{\zeta} \omega)$ at the question what, exactly, is true about them [scil. cases of the same sort of (Syn)]. Sometimes I get really dizzy looking at them

the verb $\theta \alpha v \mu \alpha \dot{\zeta} \omega$ thus circles back to the verbal adjective $\theta \alpha v \mu \alpha \sigma \tau \dot{\alpha}$ at I54b6. At this point, then, Socrates maximises the force of the confession above, by characterising wonder as the only source of philosophical inquiry. Theaetetus' wonder, indeed, is generated and sustained by a felt conceptual discontinuity that philosophy aims to repair in order to remain intelligible to itself.

\section{Works cited}

Bluck, R. S. (I96I) 'The puzzles of size and number in Plato's Theaetetus', PCPhS 7, 7-9.

Bostock, D. (I988) Plato's 'Theaetetus', Oxford.

Brown, M. S. (I969) 'Theaetetus. Knowledge as continued learning', JHPh 7, 359-379.

Burnyeat, M. (I979) 'Conflicting appearances', PBA 65, 69-III.

Campbell, L. (I86I) The 'Theaetetus' of Plato, Oxford.

Cooper, J. M. (I990) Plato's 'Theaetetus' (reprint of 1967 Harvard Ph.D. Dissertation), New York.

Cornford, F. M. (1935) Plato's theory of knowledge: The 'Theaetetus' and the 'Sophist' of Plato, translated with a running commentary, London.

Desjardins, R. (I990) The rational enterprise: logos in Plato's 'Theaetetus', Albany, NY.

Fine, G. (1996) 'Conficting appearances: Theaetetus I53d-I54b', in C. Gill, M. McCabe (eds.) Form and argument in late Plato, Oxford, 105-33; also in Fine, G. (2003) Plato on knowledge and forms: selected essays, Oxford, I6o-83.

Geach, P. T. (1969) God and the soul, London.

Hackforth, R. (1957) 'Notes on Plato's "Theaetetus"', Mnemosyne Io, I28-40.

Haring, E. S. (I992) 'Socratic duplicity: Theaetetus I54bi-I56a3', RMeta 45 525-42.

Kirwan, C. (I974) 'Plato and relativity', Phronesis I9, II2-29.

Lee, M.-K. (2005) Epistemology after Protagoras, Oxford.

McDowell, J. (I973) Plato. Theaetetus, Oxford.

Narcy, M. (1995) Platon: 'Théétète', Paris.

Polansky, R. M. (I992) Philosophy and knowledge: A commentary on Plato's 'Theaetetus', Lewisburg-London.

Ross, W. D. (1953) Plato's theory of ideas, Oxford.

Russell, B. (1945) A history of western philosophy, New York.

van Eck, J. (2009) 'Moving like a stream: Protagoras' Heracliteanism in Plato's Theaetetus', OSAPh 36, I97-246. 